\title{
A UNIVERSIDADE E O ENSINO FUNDAMENTAL E MÉDIO: ESTREITANDO RELAÇÕES POR MEIO DE ABORDAGENS METODOLÓGICAS
}

\author{
Ana Cristina Santos Duarte ${ }^{1}$ \\ Marcos Lopes de Souza ${ }^{2}$ \\ Marina Nascimento ${ }^{3}$
}

\section{RESUMO}

Este artigo é resultado de um projeto de extensão desenvolvido e financiado pela Universidade Estadual do Sudoeste da Bahia (UESB) desde 2005. O projeto integra as atividades do Laboratório de Ensino de Biologia (LEBio) e visa à aproximação da universidade com a comunidade escolar, por meio de atividades dinâmicas, não convencionais, que envolvem conteúdos curriculares de Ciências e Biologia, trabalhados ou não no ensino fundamental e no médio. Portanto, como princípios norteadores para a reflexão, compreensão e construção de conhecimentos relacionados à área. As atividades do projeto envolveram a seleção de temas atuais e emergentes de interesse do educando, para o desenvolvimento de mini-cursos e oficinas. Destes participaram os discentes da graduação em Ciências Biológicas, que

\footnotetext{
${ }^{1}$ Doutora, Professora da área de Educação do Departamento de Ciências Biológicas da Universidade Estadual do Sudoeste da Bahia (UESB), membro do Grupo de Estudo e Pesquisa em Formação de Educadores em Ciências. E-mail: tinaduarte2@gmail.com

${ }^{2}$ Doutor, Professor da área de Educação do Departamento de Ciências Biológicas da UESB, membro do Grupo de Estudo e Pesquisa em Formação de Educadores em Ciências. E-mail: marcoslsouza@ig.com.br

${ }^{3}$ Discente do Curso de Ciências Biológicas da UESB, Bolsista do Projeto em 2011. E-mail: as_gemeas16@hotmail.com

\begin{tabular}{l|l|l|l|l}
\hline Revista Extensão \& Cidadania & Vitória da Conquista & v. 1, n. 1 & p. 27-39 & jan./jun. 2013 \\
\hline
\end{tabular}
}


tiveram a oportunidade para uma prática docente de forma não convencional, capaz de estimular o exercício profissional. O enfoque dos temas se deu não só no domínio cognitivo, mas também no domínio afetivo, com o objetivo de ampliar a capacidade, do aluno, de conhecer e relacionar-se consigo mesmo e com o outro. A metodologia utilizada é participativa e dinâmica, a fim de proporcionar a aprendizagem e a integração da área de Ciências e Biologia com outras áreas do conhecimento. $\mathrm{O}$ trabalho teve a parceria de escolas públicas e buscou resgatar o valor social da universidade na comunidade, para estreitar as relações entre a universidade e o ensino fundamental e o médio.

Palavras-chave: Aprendizagem. Metodologias. Universidade. Comunidade.

\title{
The university and the elementary and high school: narrow relations through methodological approach means.
}

\begin{abstract}
The article is the result of an extension project, developed and funded by the State University of Southwest Bahia (UESB) since 2005, it integrates the activities developed in the Laboratory biology teaching (LEBio) in order to approach the University of school community through dynamic activities, unconventional of teaching, involving curricula of the teaching of Science and Biologywhether or not worked in elementary and middle school. Therefore,as guiding principles for reflection, understanding and knowledge related to construction of Science/Biology themes are selectedcurrent/emerging and interest of learners with whom we develop short courses and workshops, involving undergraduate students in biological sciences, intending to offer the practice of student teaching in an unconventional way, encouraging them to exercise the professional side. During the activities, we focus on emerging issues/currentrelated not only to the cognitive domain, but also the affective domain, increasing the capacity to know and relate to yourself and with the other. For this purpose, the methodology used isparticipatory and dynamic in order to provide learning and the integration of science and biology with other areas of knowledge, given the diversity in the way of learning and expressing learning. We seek to work in partnership with public schools, restoring the social value of the university community, thus narrowing the relationship between the university and elementary and secondary education.
\end{abstract}

Keywords: Learning. Methodologies. University. Community. 


\section{Introdução}

A escola tem como um dos papeis fundamentais $\mathrm{O}$ desenvolvimento dos indivíduos de maneira integral, com isso contribui para uma boa qualidade de vida e para o exercício da cidadania, que ocorre, entre outras formas, por meio do respeito à diversidade dos seres humanos e da aceitação do outro, com seus desejos, limites e possibilidades. Portanto, deve levar em consideração o ser humano em todas as suas dimensões biopsicossocial.

Essas e outras funções da educação são respaldadas legalmente, principalmente pela Constituição Federal (1988), pela Lei de Diretrizes e Bases da Educação Nacional (LDB 1996) e pelos Parâmetros Curriculares Nacionais (PCNs 1997), que direcionam as discussões e o desenvolvimento de projetos educacionais, das práticas pedagógicas e da formação/atualização profissional.

Observamos que ainda existe uma grande carência na educação básica no que se refere às abordagens metodológicas para o ensino de ciências e biologia que integrem as diversas áreas do saber e valorizem o aluno como um todo.

Nessa perspectiva, o projeto de extensão "A universidade e o ensino fundamental e médio: estreitando relações por meio de uma abordagem metodológica", que integra as atividades desenvolvidas no Laboratório de Ensino de Biologia (LEBio), apresenta relevância científico-educacional e social, uma vez que promove a aprendizagem do ensino de ciências e biologia por meio de abordagens metodológicas não convencionais, trabalhando com temas emergentes/atuais e de interesse da comunidade, bem como integrando diversas áreas do conhecimento.

As ações desenvolvidas pelo projeto foram relevantes para a atualização e motivação de educandos do ensino fundamental e médio, bem como para os futuros profissionais (atuais alunos do curso de graduação em Ciências Biológicas). Estas ações tiveram o objetivo de proporcionar meios para o desenvolvimento do exercício profissional de forma não convencional, valorizando o desenvolvimento de domínios cognitivos e afetivos. 
O projeto tem como principal objetivo estreitar as relações entre a universidade e o ensino fundamental e o médio por meio de uma abordagem metodológica para o ensino de ciências e biologia, bem como viabilizar uma maior interação entre licenciandos do curso de Ciências Biológicas e educandos das escolas de ensino fundamental e ensino médio e proporcionar aos graduandos uma vivência do exercício profissional ao desenvolver atividades utilizando abordagens metodológicas não convencionais.

\section{Breve Revisão de Literatura:}

\subsection{O ensino de Ciências}

Nas últimas décadas, assistimos a uma mudança de enfoque no ensino de ciências. Ao invés de ser vista como um corpo de conhecimentos estabelecidos, a ciência passou a ser tratada como uma atividade humana que se acentua de forma progressiva ao caráter experimental dos processos e procedimentos científicos.

$\mathrm{O}$ foco do ensino de ciências naturais não pode se limitar à promoção de mudanças conceituais ou ao aprendizado do conhecimento científico. É necessário também buscar mudanças no que se refere à metodologia e à atitude dos alunos, bem como ressignificar o ensino para construir um processo de aprendizagem no qual, professores e alunos, possam interagir de forma crítica e reflexiva ao ensinar e aprender.

Assim, diversas alternativas metodológicas objetivam relacionar os conteúdos ensinados com o cotidiano. Essa ligação ocorre, geralmente, por meio da observação de modelos e analogias, do desenvolvimento de propostas mais adequadas para a formação docente, da valorização da experimentação e da produção de materiais didáticos alternativos.

Surge então a necessidade de repensar a prática educativa e evitar o modelo de ensino que apenas reproduz os conteúdos sem nenhuma significação para o educando, que está ligado à perspectiva conservadora da educação. 
Como acontece em outras áreas, o ensino de ciências no Brasil tem se pautado quase exclusivamente pelo uso de manuais didáticos. Entretanto, as pesquisas educacionais e as discussões entre os especialistas apontam para a utilização de outros recursos (filmes, jornais, livros paradidáticos, revistas, entre outros) como possíveis alternativas para a superação dos modelos tradicionais e, principalmente, para a promoção de aprendizagens mais significativas.

$\mathrm{Na}$ aprendizagem de ciências naturais, as atividades experimentais devem assegurar que a relação teoria-prática não se transforme numa dicotomia. As experiências despertam em geral um grande interesse nos alunos, além de propiciar situações de investigação, que quando bem planejadas constituem momentos particularmente ricos no processo de ensino-aprendizagem.

O ensino das ciências está voltado prioritariamente para uma compreensão mais aprofundada dos conceitos, das ideias dos alunos e dos professores, que busca constantemente uma articulação com os procedimentos didáticos necessários para o envolvimento dos alunos no processo de aprendizagem.

$\mathrm{Na}$ busca de atender de forma crítica às novas demandas de ensino de ciências, é fundamental desenvolver uma prática docente consciente, fundamentada na articulação entre os aspectos teóricos e práticos da ação educativa.

Os alunos devem aprender conceitos básicos, vivenciar o método científico e analisar as implicações sociais do desenvolvimento da biologia, resta ao professor, escolher os conteúdos correspondentes mais relevantes, fundamentais e atuais. Em seguida devem-se selecionar as atividades e experiências que melhor levem à consecução dos objetivos propostos (KRASILCHIK, 2004).

Compreendemos a necessidade de articulação entre os aspectos teóricos e práticos da ação docente e a necessidade de refletir sobre as formas de acesso ao conhecimento e a sua configuração na escola, pois, no contexto da sociedade do conhecimento, a educação e os métodos tradicionais que são baseados na reprodução do conhecimento, 
tornam-se ineficazes quando a ciência, tecnologia e sociedade têm, obrigatoriamente, de relacionarem-se.

\subsection{A formação de professores}

A formação de professores para atuar no Ensino Fundamental e no Médio tem sido um desafio para os cursos de licenciatura das universidades brasileiras, mesmo porque, esta formação inicial no processo total de formação docente é condição necessária, mas não suficiente em si mesma, para conseguir professores mais qualificados (MIZUKAMI et al., 2002).

Durante muito tempo na história da educação, a formação inicial era concebida como o único ou o momento mais importante na formação do educador. Nessa forma de conceber a formação de professores, priorizavase o acúmulo de conhecimentos e técnicas para que, posteriormente, o professor pudesse aplicá-los (MIZUKAMI et al., 2002). Sabe-se que essa maneira de entender a formação de professores tinha como parâmetro às situações idealizadas nas práticas educativas, o que se difere do que ocorre no cotidiano escolar. Assim sendo, este tipo de concepção da formação de professores pouco contribui para a aprendizagem docente, pois a realidade educacional apresenta certa complexidade e vai além de problemas meramente técnicos e instrumentais (MIZUKAMI et al., 2002).

Agora, pensando na formação de professores numa outra concepção, como um continuum, supera-se esta ideia restrita e a compreende como um processo que se inicia desde a vivência discente, perpassa pela formação básica e continua na vivência profissional. Observamos então que estas etapas estão interligadas. Neste caso, a reflexão é um dos elementos que pode permitir a interação entre esses diversos momentos (NÓVOA, 1992).

Por outro lado, a formação inicial de professores é o momento em que esses futuros educadores entram em contato com o universo escolar na perspectiva da docência. É sabido que este primeiro contato, a depender da orientação, pode, ao invés de permitir uma reflexão constante sobre o ensinar, gerar a insatisfação dos alunos. Conforme Nóvoa (1992), para que se possa viabilizar uma melhor formação aos professores, é necessário que eles compreendam esta complexidade do ato de ensinar por meio da 
vivência prática do "ser professor" e, dessa maneira, consigam além de perceber grande parte dos problemas do processo ensino-aprendizagem, elaborar meios de lidar com toda essa problemática.

É notório que a formação inicial apresenta diversas problemáticas, como: desconhecimento por parte de professores das discussões atuais sobre o processo de ensino-aprendizagem ou mesmo o descompasso entre as disciplinas de conteúdo específico e pedagógico (GIL-PÉREZ; CARVALHO, 1995). No entanto, ela pode, na medida em que oferece ao aluno uma reflexão sobre a educação em geral e a prática pedagógica, proporcionar um bom suporte, a fim de prepará-lo para atuar na profissão.

As pesquisas na área de formação de professores têm demonstrado que os educadores apresentam ideias, atitudes e comportamentos em relação ao ensino e aprendizagem de ciências construídas ao longo de sua trajetória de vida, em especial, no momento em que foram alunos (GIL-PERÉZ, 2001). Essas ideias estão tão arraigadas que se torna difícil de reestruturá-las, porém o que se tem proposto é a formação entendida como construção de conhecimentos que tem como base uma prática reflexiva. Conforme Gil-Peréz (2001), para viabilizar uma formação nessa perspectiva, os futuros professores têm que constantemente entrar em contato com a prática pedagógica e favorecer a vivência de propostas inovadoras, com isso, construírem reflexões didáticas explícitas.

Assim sendo, uma das formas de os futuros professores vivenciarem o "ser professor" é por meio da regência de aulas em escolas e até mesmo elaborar e ministrar cursos e/ou mini-cursos a serem oferecidos aos alunos. Nessa perspectiva, os futuros docentes se deparam com o universo escolar e passam a interagir não só com os estudantes do ensino fundamental e do médio, mas também com os professores que estão em exercício nas escolas. Aqui, é importante a participação de professores da universidade para intermediar um diálogo efetivo e problematizador entre os futuros professores e aqueles em atuação (VILLANI et al., 2002). 
A interação entre universidade e escola também é justificada quando se analisa pesquisas que caracterizam os professores em exercício. Grande parte dos trabalhos, que discutem a formação continuada de professores de Ciências e Biologia, indica que os professores das escolas vivem, atualmente, em determinadas circunstâncias que tornam difícil a reflexão sobre seu papel no processo de escolarização, como: baixos salários, violência escolar e jornada diária longa. Além disso, no cotidiano da sala de aula, os professores enfrentam diversas situações que não vivenciam durante a formação inicial. É necessário, portanto, a existência de momentos em que os educadores possam discutir as problemáticas do seu cotidiano escolar. A ausência, desses momentos de discussão, acarretaria na aceitação dos problemas do dia a dia, com isso os professores se sentiriam incapazes de mudar a triste realidade que estão vivenciando. (PÓRLAN; RIVERO, 1998).

Por outro lado, quem forma os professores que estão nas escolas é a universidade, que é questionada, muitas vezes, por pouco contribuir para a formação permanente dos professores presentes na rede pública. Dessa forma, ao propormos este projeto de extensão, objetivamos possibilitar uma maior interação entre esses futuros educadores, os alunos das escolas públicas e os professores em exercício nas escolas. Nesse ínterim, os futuros professores conseguem estabelecer um espaço em que possam vivenciar a aprendizagem docente; os alunos da escola pública podem interagir com outras formas de se pensar e ensinar ciências/biologia e os professores em exercício podem estabelecer um espaço na universidade pública para dialogar sobre algumas das problemáticas vivenciadas no cotidiano escolar e assim, contribuir para que eles ressignifiquem a sua prática educativa.

\section{Metodologia}

O projeto é desenvolvido principalmente nas escolas públicas do ensino fundamental e médio da cidade de Jequié ou circunvizinhas, também são desenvolvidas atividades na própria UESB (Campus 
de Jequié). Participam do projeto, discentes e docentes da educação básica, discentes da graduação e pessoas da comunidade interessadas nos temas. A metodologia utilizada é dinâmica e participativa, de forma que desperta o interesse, motiva e envolve os educandos nas atividades selecionadas, geralmente, os temas abordados nestas são sociais, emergentes e de interesse dos alunos. Estas atividades são desenvolvidas de maneira não convencionais, que contribuem para o processo de aprendizagem de ciências e biologia, são elas: mini-cursos, oficinas, jogos, atividades experimentais, demonstrações, etc.

Os temas e conteúdos trabalhados referem-se principalmente aos temas transversais como: sexualidade, educação ambiental, saúde, ética e cidadania; e a temas voltados para a educação científica como: microscopia, células animal e vegetal, extração de DNA, conhecer e prevenir a Dengue, etc.

Vale ressaltar que a metodologia utilizada no projeto de extensão permite a articulação com o ensino e a pesquisa. A articulação com o ensino ocorre, principalmente, por meio da participação de discentes dos cursos de licenciatura da UESB e discentes do ensino fundamental e do ensino médio, que proporciona a vivência de práticas pedagógicas não convencionais. E a relação com a pesquisa ocorre por meio de relatos de experiências e monografias de final de curso. Outro fator importante é o surgimento de novas pesquisas no campo da educação, estas objetivam divulgar os resultados obtidos por meio da utilização de metodologias alternativas para a melhoria do processo ensinoaprendizagem de ciências, bem como as necessidades formativas para os educadores em ciências.

A avaliação e o acompanhamento do projeto ocorrem de forma contínua durante o desenvolvimento de cada atividade por meio da observação direta, dos relatos orais dos participantes e das fichas de avaliação preenchidas ao final das atividades.

Contamos com o apoio de bolsistas remunerados e voluntários que auxiliam na divulgação, planejamento, elaboração e execução das atividades. 


\section{Resultados e análise}

O projeto de extensão "A universidade e o ensino fundamental e médio: estreitando relações por meio de abordagens metodológicas", teve início em 2005 e continua em funcionamento. Durante estes anos temos proporcionado discussões, debates, informações e, sobretudo, mudança de comportamento nos discentes e nos docentes. Contribuímos para uma reflexão a respeito da importância do papel exercido pela universidade na comunidade, bem como para a construção do conhecimento por meio de abordagens metodológicas não convencionais no processo de ensino-aprendizagem de ciências e biologia. No quadro abaixo apresentamos os resultados:

Quadro 1 - Demonstrativo do número de atividades e beneficiados

\begin{tabular}{|l|c|c|}
\hline Ano & Número de tividades & Número debeneficiados \\
\hline 2005 & 14 & 155 \\
\hline 2007 & 6 & 111 \\
\hline 2008 & 8 & 104 \\
\hline 2009 & 10 & 729 \\
\hline 2010 & 15 & 1.035 \\
\hline 2011 & 14 & 1.031 \\
\hline
\end{tabular}

Fonte: Relatórios.

Observa-se que em 2009 houve um aumento significativo do número de atividades desenvolvidas e de beneficiados; inferimos que este aumento, deva-se ao fato de termos mais professores envolvidos na execução do projeto e a aquisição de um carro "Laboratório Móvel de Ciências", que foi adquirido pelo Convênio 034/2008 UESB/ SECTI (Secretaria de Ciências e Tecnologia da Informação). O carro facilitou o deslocamento, dos participantes e dos monitores do projeto, da UESB para as escolas e praça pública; além disso, ele chamava a atenção e as escolas solicitavam a nossa presença em eventos científicos e culturais realizados.

Durante o desenvolvimento das atividades (minicursos, oficinas, exposição do laboratório móvel, aulas práticas/experimentação e outras) percebeu-se o envolvimento dos participantes, a curiosidade, o interesse e a motivação. 
Segundo Delizoicov (2002, p. 163), o ponto de partida do processo educativo é a aproximação do conhecimento com o dia a dia dos discentes, nesse sentido, a escolha dos temas a serem trabalhados deve vincular-se à realidade e às necessidades dos alunos, "utilizando como critério de seleção seu caráter significativo, podendo surgir na família, na escola, em suas relações sociais, culturais, intelectuais e emocionais". Destaca-se, ainda, o papel do professor no processo de aprendizagem.

Só é possível ao professor mediar, criar condições, facilitar a ação do aluno de aprender, ao vincular um conhecimento como seu porta-voz. É uma coisa tão óbvia, que, às vezes, se deixa de levá-la em consideração (DELIZOICOV, 2002, p. 122).

Para Freire (1983), a prática pedagógica não pode ser entendida como um conjunto de receitas para a ação dos professores, mas como um processo que permite ação-reflexão-ação, bem como a valorização do aluno e do processo de aprendizagem.

Destacamos também como resultado, a articulação entre o ensino, a pesquisa e a extensão, principalmente por proporcionar aos discentes dos cursos de licenciatura da UESB, a vivência de práticas pedagógicas, por meio dos estágios supervisionados que ocasionou no despertar do interesse pela pesquisa no campo da educação em ciências.

\section{Considerações finais}

Durante visitas às escolas publicas do município, para divulgação ou execução de atividades referente ao projeto, observou-se que a maioria das escolas não possuía material didático nem estrutura adequada, como, um Laboratório de Ciências para o desenvolvimento de determinadas atividades didáticas. Constatou-se também que a maioria dos educadores apresentava dificuldades na utilização dos 
equipamentos laboratoriais, além de explorarem uma concepção empirista sobre a construção do conhecimento. Durante as atividades do projeto, procuramos construir novos conceitos e hábitos que permitiam uma melhoria na qualificação dos educadores e uma aprendizagem mais significativa para os discentes. Os resultados indicam que a execução do projeto tem proporcionado aos educadores uma reflexão acerca da importância da utilização de metodologias variadas como instrumento de motivação e invenção. Os objetivos previstos foram alcançados de maneira satisfatória e a metodologia utilizada tem se revelado adequada e pertinente ao alcance dos objetivos, com isso verificamos o interesse e a necessidade de tais ações e atividades, principalmente, no sentido de contribuir para uma melhor aproximação da comunidade com a universidade e desmistificar a ideia de que a universidade é fechada em seus muros, além de proporcionar aprendizagens mais significativas relacionadas ao ensino de ciências e biologia.

A realização do projeto foi de grande importância para a comunidade Jequieense e principalmente para a universidade, pois é, sem dúvida, uma ponte entre a universidade e a comunidade, que possibilita o envolvimento de discentes da graduação em Ciências Biológicas, enriquecendo suas experiências acadêmicas e profissionais, assim contribui para a expansão do conhecimento científicotecnológico nos ambientes de trabalho, principalmente em escolas públicas da educação básica.

\section{Referências}

BRASIL. Congresso Nacional. Constituição Federal. Brasília, 1988.

- Secretaria da Educação Fundamental. Parâmetros Curriculares Nacionais (PCNs): Ciências Naturais. Brasília: MEC/SEF, 1997.

- Secretaria da Educação. Lei de Diretrizes e Bases da Educação Nacional (LDB). Lei no 9.394, 20 de dezembro de 1996. Brasília: MEC, 1996. 
DELIZOICOV, Demétrio. Ensino de Ciências: fundamentos e métodos. São Paulo: Cortez, 2002.

FREIRE, Paulo. Educaşão como prática de liberdade. Rio de janeiro: Paz e Terra, 1983.

GIL-PÉREZ, D. Orientações didáticas para a formação continuada de professores de Ciências. In: MENEZES, L. C. Formação continuada de professores de ciências no contexto ibero-americano. 2. ed. Campinas: Autores Associados, 2001.

GIL-PÉREZ, D.; CARVALHO, A. M. P. Formação de professores de ciências: tendências e inovações. 2. ed. São Paulo: Cortez, 1995.

KRASILCHIK, M. Prática de ensino de Biologia. São Paulo: EDUSP, 2004.

MIZUKAMI, M. G. N. et al. Escola e aprendizagem da docência: processos de investigação e formação. São Carlos: EdUFSCar, 2002.

NÓVOA, A. (Org.). Os professores e a sua formação. Lisboa: Dom Quixote, 1992.

PÓRLAN, R.; RIVERO, A. El conocimiento de los professores: una propuesta formativa in el área de ciencias. Sevilha: Diada, 1998.

VILLANI, A.; PACCA, J. L. A.; FREITAS, D. Formação do professor de Ciências no Brasil: tarefa impossível? In: ENCONTRO NACIONAL DE PESQUISA EM ENSINO DE FÍSICA, 8., 2002, Águas de Lindóia. Atas... São Paulo: Sociedade Brasileira de Física, v. único, 2002. 